\title{
Synchronous Burkitt's Lymphoma of Breast and Colon in a Female Patient: A Report of a Case and Review of Literature
}

\author{
(1) Mohammad Eslami JOUYBARi' ${ }^{1}$, (1) Anahita NOSRATi' ${ }^{2,6}$, (1) Elham Sadat BANIMOSTAFAVi ${ }^{3}$, \\ (1) Mohammad Mehdi Ghaffari HAMEDANi ${ }^{4}$, (1) Abdolrahim AHMADi ${ }^{5}$, (1) Marzieh BATHAEi ${ }^{2,6}$ \\ 'Department of Oncology, Gastrointestinal Cancer Research Center, Mazandaran University of Medical Science, Sari-Iran \\ 2Department of Pathology, Imam Khomeini Hospital, Mazandaran University of Medical Science, Sari, Iran \\ ${ }^{3}$ Department of Radiology, Imam Khomeini Hospital, Mazandaran University Of Medical Science, Sari, Iran \\ ${ }^{4}$ Department of Surgery, Imam Khomeini Hospital, Mazandaran University of Medical Science, Sari, Iran \\ ${ }^{5}$ Imam Khomeini Hospital, Mazandaran University of Medical science, Amol, Iran \\ ${ }^{6}$ Gastrointestinal Cancer Research Center, Mazandaran University of Medical science, Sari, Iran
}

\begin{abstract}
SUMMARY
Burkitt's lymphoma (BL) is a highly aggressive cancer of B-cells, which is more prevalent in African children. Extranodal involvement of the BL is not a common entity. Herein, we report a young woman who referred to University hospital due to rectorrhagia and breast swelling. Colonoscopy examination revealed a large tumoral lesion of $5 \times 6 \mathrm{~cm}$ with superficial ulceration in proximal of ascending colon. Computed tomography (CT) scan of the abdomen showed a $55 \times 42 \mathrm{~mm}$ mass in ascending colon and caecum. No lymphadenopathy, splenomegaly and hepatomegaly were reported. Breast ultrasound was performed showed a $24 \times 11 \mathrm{~mm}$ hypoechoic heterogeneous mass in the left breast. Bone marrow biopsy was normal. Immunohistochemical assay of colon and breast biopsies confirmed the diagnosis of primary BL. After four courses of chemotherapy, PET-CT revealed complete remission and no sign of metastasis. Since BL is a rapidly-growing neoplasm, prompt diagnosis and treatment can prevent unnecessary surgery and consequences of delay in treatment.
\end{abstract}

Keywords: breast neoplasm; Burkitt lymphoma; colon neoplasm; PET-CT.

Copyright $\odot$ 2020, Turkish Society for Radiation Oncology

\section{Introduction}

Burkitt's lymphoma (BL) is a B-cell malignancy in non-Hodgkin lymphoma category. BL is a rare but aggressive cancer that mainly affects African young children associated with Epstein-Barr virus infection as endemic forms. It also may present concerning immunodeficiency in HIV positive subjects or organ transplant recipients.[1] Sporadic variant of the BL is not specific to a certain geographical region and often involves gastrointestinal and respiratory system.[2] Lymphoma represents a rare type of primary breast malignancy (less than 1\%) with diffuse large B-cell lymphoma (DLBCL) as the most common; BL of the breast is extremely unusual.[3] We report a rare case of BL with ascending colon and breast involvement presenting with rectorrhagia and unilateral breast mass.

\section{Case Report}

A 29 years-old woman presented with a 40-days history of abdominal pain and diarrhea to University clinic. At attendance, there was a complaint of rectorrhagia.
Dr. Mohammad Eslami JOUYBARi

Department of Oncology,

Gastrointestinal Cancer Research Center,

Mazandaran University of Medical Science

Sari-Iran

E-mail:drsinaeslami@gmail.com 
The other symptoms were nausea, changes in bowel habits and weight loss, the sensation of breast mass since two weeks before her admission to the hospital. There was no history suggestive of any fever and night sweats. She had a 3-year-old child and was not pregnant or breast-feeding at the time of referral.

Her routine investigations revealed hemoglobin of 11.7 , white cell count of $3100 / \mathrm{mm}^{3}$, platelet count of $240000 / \mathrm{mm}^{3}$, erythrocyte sedimentation rate (ESR) was $19 \mathrm{~mm}$, uric acid was $10 \mathrm{mg} / \mathrm{dl}$, liver functional tests and electrolytes were within normal range and beta2 microglobulin was 1.47 .

Colonoscopy examination revealed a large tumoral lesion of $5 \times 6 \mathrm{~cm}$ with superficial ulceration in proximal of ascending colon. Computed tomography (CT) scan of the abdomen showed a $55 \times 42 \mathrm{~mm}$ mass in ascending colon and caecum. No lymphadenopathy, no splenomegaly and no hepatomegaly. Endoscopic ultrasonography was normal. Breast ultrasound was performed, which showed a $24 \times 11 \mathrm{~mm}$ hypoechoic heterogeneous mass in the left breast. Color Doppler revealed peripheral and central vascularity. Histopathological examination of colonic and breast biopsies revealed a malignant neoplasm with ulceration composed of fibrin deposition, cell debris and neutrophilic infiltration. Extensive infiltration of atypical lymphocytes with hyperchromatic nuclei, regular borders and scattered cytoplasm were observed. Also, a few mitotic figures and a segment of necrotic tissue were noted. No grandular structures and epithelial cells were reported.

Bone marrow biopsy was normal and immunohistochemistry (IHC) result was as follows: CD79a positive in background B-cells, PAX5 and CD38 positive in neoplastic B-cells, CD43, CD5 and CD3 positive in background T-cells, CD45 positive diffusely, BCL6 positive, CD23, cyclin D1, CD56, MNF116, TdT, CD99 and chromogranin were negative in tumor cells. MYC was positive in more than $80 \%$ of the tumor cells and ki67 was positive in more than $95 \%$ of tumor cells, so the findings were consistent with Burkitt's lymphoma. Soon, she received immune-chemotherapy using Rituximab and Hyper-CVAD (Cyclophosphamide, Vincristine, Adriamycin, and Dexamethasone) regimen. Since the closest time to schedule a PET scan was one month later (due to limitations) and because of disease nature, it was not possible to order it before chemotherapy. One month later, PET scan revealed no evidence in favor of metabolically active lesion throughout the suggesting a complete remission of the disease (Fig. 1). Patient's first visit was in August 2019 and the last follow-up was in January 2020, when the patient showed no sign of disease progression. The patient's consent was obtained for this case study.
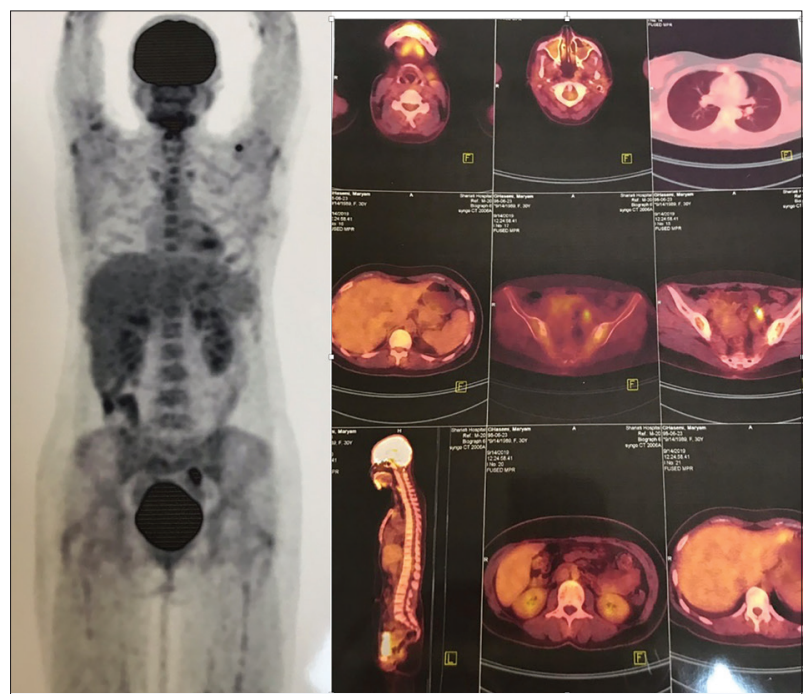

Fig. 1. PET scan shows no pathologic FDG uptake in the whole body (increased activity observed in left clavicle is due to enthesopathy).

\section{Discussion}

In 1958, Irish surgeon Denis Burkitt was first to describe $\mathrm{BL}$ as an unusual disease in African children.[4] While the exact etiology of BL remains unknown, several risk factors have been introduced. EBV is a human herpes virus (HHV4) with a worldwide spread that most adults are seropositive for it. This B-lymphotropic virus induces B-cell proliferation and may establish latent infection. Transformation of B-cells is mediated by viral antigens, including latent membrane proteins, nuclear antigens, non-coding and micro-RNAs. Hodgkin lymphoma (HL), diffuse large B-cell lymphoma and BL, are among B-cell neoplasms to be associated with EBV infection. $[5,6]$ Alteration and translocation of c-myc proto-oncogene (located on chromosome 8) is a hallmark presentation of BL. Myc acts as a transcription factor to control many cellular functions, including cell growth and proliferation, protein synthesis and apoptosis.[7] Overexpression of the Myc using Immunoglobulin heavy chain enhancer $[t(8 ; 14)]$ would lead to lymphoid system malignancies, including BL.[8] In endemic BL, there is also evidence of the role of Plasmodium falciparum infection in DNA damage modulated by activation-induced cytidine deaminase (AID) in this type of malignancy.[9] $\mathrm{BL}$ is a rapidly growing high-grade cancer. Sporadic type BL is more common in western regions and children with male predominance.[10] Up to $40 \%$ of extranodal involvements of lymphomas occur in the gastrointestinal system.[11] According to a study concerning children with gastrointestinal BL, 
symptoms according to frequency were reported as follows: abdominal pain and swelling, vomiting, intestinal obstruction, constipation, diarrhea, melena and rectal bleeding.[1] Therefore, lower GI bleeding in our patient may be considered as a rare symptom of BL.[12] Intussusception and obstruction of bowel can also mimic acute abdomen, which requires prompt surgical intervention. Small intestine and ileocecal region are common sites to be affected.[13]

Only approximately $0.5 \%$ of breast cancers are attributed to primary lymphoma. This rare manifestation may occur in uni- and bilateral forms. DLBCL accounts as the first prevalent subtype of primary lymphomas of the breast followed by follicular lymphoma, mucosa-associated lymphoid tissue lymphoma and BL.[14] Usually, cases are pregnant or in lactation period; therefore, the diagnosis may be missed due to suspicion of abscess. $[14,15]$ Also, breast BL is reported in association with HIV infection too.[16] Breast swelling, progressively increasing mass, pain, breast enlargement and tenderness are among man manifestation which is not different from carcinoma symptoms.[14,16-18]

The 5-year survival of BL from $43 \%$ in 1973-2001 reached 56\% in 2002-2008; however, older patients tend to have poorer survival.[19] It has also been shown that risk factors for low survival differ in children and in adults. In adults primary tumors in bone marrow, stage III and IV and in children stage IV were associated with worse survival.[20]

Also, breast BL lacks pathognomonic features in imaging modalities, including mammography and ultrasound.[21]

There is still no treatment of choice for the BL. The effectiveness of surgery is a controversial and usually dramatic response to chemotherapy is observed with complete remission.[22] As BL is a rare but aggressive entity, prompt diagnosis and rapid initiation of treatment can play a substantial role in the control and remission of it.

Informed consent: Informed consent was obtained from the patient in this study.

Peer-review: Externally peer-reviewed.

Conflict of Interest: No conflict of interest.

Authorship contributions: Concept - M.E.J.; Design M.E.J.; Supervision - M.E.J.; Materials - M.E.J.; Data collection \&/or processing - M.E.J., A.N., E.S.B., M.M.G.H.; Analysis and/or interpretation - M.E.J.; Literature search - M.B.; Writing - A.A.; Critical review - A.A.

\section{References}

1. Ghoroubi J, Mirshemirani A, Kouranloo J, Shiva Nazari. Abdominal Burkitt's lymphoma in children. Iranian Journal of Pediatric Surgery 2015;1:28.

2. Derinkuyu BE, Boyunağa Ö, Öztunalı Ç, Tekkeşin F, Damar Ç, Alımlı AG, et al. Imaging features of Burkitt lymphoma in pediatric patients. Diagn Interv Radiol 2016;22(1):95-100.

3. Wei J, Lin C, Xu C, Xi Q, Wang C. Primary Burkitt's lymphoma of the breast without Epstein-Barr virus infection: A case report and literature review. Indian J Pathol Microbiol 2015;58(4):546-9.

4. Coakley D. Denis Burkitt and his contribution to haematology/oncology. Br J Haematol 2006;135(1):17-25.

5. Rowe M, Fitzsimmons L, Bell AI. Epstein-Barr virus and Burkitt lymphoma. Chin J Cancer 2014;33(12):609-19.

6. Ali AS, Al-Shraim M, Al-Hakami AM, Jones IM. Epstein-Barr Virus: Clinical and Epidemiological Revisits and Genetic Basis of Oncogenesis. Open Virol J 2015;9:7-28.

7. Cowling VH, Turner SA, Cole MD. Burkitt's lymphoma-associated c-Myc mutations converge on a dramatically altered target gene response and implicate Nol5a/Nop56 in oncogenesis. Oncogene 2014;33(27):3519-27.

8. Yan Y, Park SS, Janz S, Eckhardt LA. In a model of immunoglobulin heavy-chain (IGH)/MYC translocation, the Igh 3 ' regulatory region induces MYC expression at the immature stage of $\mathrm{B}$ cell development. Genes Chromosomes Cancer 2007;46(10):950-9.

9. Thorley-Lawson D, Deitsch KW, Duca KA, Torgbor C. The Link between Plasmodium falciparum Malaria and Endemic Burkitt's Lymphoma-New Insight into a 50-Year-Old Enigma. PLoS Pathog 2016;12(1):e1005331.

10. Kalisz K, Alessandrino F, Beck R, Smith D, Kikano E, Ramaiya $\mathrm{NH}$, et al. An update on Burkitt lymphoma: a review of pathogenesis and multimodality imaging assessment of disease presentation, treatment response, and recurrence. Insights Imaging 2019;10(1):56.

11. Vannata B, Zucca E. Primary extranodal B-cell lymphoma: current concepts and treatment strategies. Chin Clin Oncol 2015;4(1):10.

12. Bustamante-Bernal M, Galvis J, Matos D, Sosa O, Syed $\mathrm{SH}$, Padilla O, et al. Burkitt's Lymphoma of the Rectosigmoid and Stomach Presenting as Hematochezia. Am J Case Rep 2016;17:89-92.

13. Hoxha FT, Hashani SI, Krasniqi AS, Kurshumliu FI, Komoni DS, Hasimja SM, et al. Intussusceptions as 
acute abdomen caused by Burkitt lymphoma: a case report. Cases J 2009;2:9322.

14. Janbabai G, Kayedimajd S, Alian S, Naghshvar F, Rashidi M, Farazmandfar T. Bilateral breast swelling in a 23-year-old woman with Burkitt lymphoma. J Res Med Sci 2012;17(12):1188-91.

15. Sultan N, Khalid M, Khan SR, Khan F. Non-Hodgkin's lymphoma of the breast presenting as breast abscess during pregnancy. J Coll Physicians Surg Pak 2012;22(10):657-8.

16. Traoré B, Fondrevelle ME, Condé M, Chassagne-Clément C, Kourouma T, Keita AM, et al. Primary Breast Burkitt's Lymphoma in an HIV-Infected Woman. Case Rep Med 2015;2015:792041.

17. Esserman L, Sexton R, Yu QQ, Cabello-Inchausti B. Mammographic, sonographic, and pathologic characteristics of Burkitt's lymphoma in a patient referred for diagnostic mammography. AJR Am J Roentgenol 2006;186(4):1029-32.
18. Ogawa T, Mizutani M, Yabana T, Miyahara S, Murabayashi K. A Case of Burkitt's Lymphoma Involving Both Breasts. Breast Cancer 2005;12(3):234-7.

19. Costa LJ, Xavier AC, Wahlquist AE, Hill EG. Trends in survival of patients with Burkitt lymphoma/leukemia in the USA: an analysis of 3691 cases. Blood 2013;121(24):4861-6.

20. Mukhtar F, Boffetta P, Risch HA, Park JY, Bubu OM, Womack L, et al. Survival predictors of Burkitt's lymphoma in children, adults and elderly in the United States during 2000-2013. Int J Cancer 2017;140(7):1494-1502.

21. Offodile RS, Arce V, Cross J, Reed J, Beech DJ. Primary Breast Lymphoma: A Rare Clinical Entity. World J Oncol 2011;2(3):147-150.

22. Musallam KM, Taher AT, Shamseddine AI. Burkitt's lymphoma of the colon and bronchi: three case reports. Cases J 2008;1(1):15. 